\title{
Arcobriga, Segontia Lanca, Ocilis y Cortona. En torno a los nombres indígenas de tres oppida celtibéricos
}

\section{Arcobriga, Segontia Lanca, Ocilis and Cortona. Around the Celtiberian names of three oppida}

\author{
GABRIEL BARTOLOMÉ BELLÓN \\ Departamento de Prehistoria Historia Antigua y Arqueología \\ Universidad Complutense de Madrid \\ gabartol@ucm.es \\ https://orcid.org/0000-0003-0369-1938
}

\begin{abstract}
Resumen
La identificación de los nombres de los oppida del final de la Edad del Hierro ha despertado el interés de los historiadores y arqueólogos desde la Plena Edad Media. A lo largo de los siglos, especialmente en los últimos doscientos años, han sido numerosas las propuestas por ubicar en localidades y yacimientos concretos los topónimos de ciudades prerromanas y romanas citadas por las fuentes griegas y romanas y por los documentos epigráficos. En este artículo abordamos los casos de tres yacimientos de la provincia de Soria que se han vinculado con diferentes oppida celtibéricos y ciudades romanas, sin tener, en ocasiones, los suficientes argumentos para ello: Medinaceli, identificado tradicionalmente con Ocilis y, en las últimas décadas, también con Cortona y Segontia; las Ruinas Ciclópeas de Santa María de Huerta y Granja de San Pedro, donde se ha situado la Arcobriga prerromana; Las Quintanas-La Cuesta del Moro de Langa de Duero vinculado, desde su descubrimiento y excavación por Blas de Taracena, con Segontia Lanca.
\end{abstract}

Palabras clave: Cultura celtibérica, Alto Imperio, Alto Duero, Alto Jalón, Medinaceli, Ruinas Ciclópeas

\section{Abstract}

The identification of the oppida's names has aroused the interest of historians and archaeologists since the High Middle Ages. In the last two hundred years, there have been numerous proposals to locate in specific localities and sites the names of pre-Roman and Roman cities cited by Greek and Roman sources and by epigraphic documents. In this paper we study the cases of three sites in the province of Soria that have been identified with different Celtiberian oppida and Roman cities, without having, in some cases, sufficient arguments to do so: Medinaceli, traditionally identified with Ocilis and, in recent decades, also with Cortona and Segontia; the Ruinas Ciclópeas of Santa María de Huerta and Granja de San Pedro, where the pre-Roman Arcobriga has been located; Las Quintanas-La Cuesta del Moro of Langa de Duero linked since its discovery and excavation by Blas de Taracena with Segontia Lanca.

Key words: Celtiberian culture, Roman Empire, Douro Valley, Jalon Valley, Medinaceli, Ruinas Ciclópeas 


\section{Introducción}

La ubicación e identificación de los oppida del final de la Edad del Hierro ha despertado el interés de los eruditos, historiadores y arqueólogos que se han adentrado en el estudio de los pueblos que habitaron la península ibérica. Ya en el siglo xiII el arzobispo de Toledo, Rodrigo Jiménez de Rada, en diferentes pasajes de sus obras históricas, propuso identificar ciertas ciudades indígenas y romanas con lugares concretos. A partir de ese momento, los intentos por ubicar las antiguas ciudades citadas en las obras clásicas han sido una constante. Progresivamente, los investigadores han podido contar con nuevas fuentes que superaban muy ampliamente las que tuvo a su alcance Jiménez de Rada, incorporándose nuevos escritos de historiadores y geógrafos griegos y romanos, fuentes epigráficas de distinto tipo y, finalmente, las de carácter arqueológico. Sin embargo, conocer la ubicación exacta o aproximada de los oppida citados en las fuentes epigráficas y documentales no es fundamental para hacer arqueología e historia de la protohistoria peninsular. Es evidente que su desconocimiento nos priva de un acercamiento preciso al devenir concreto de ciertos acontecimientos; sin embargo, no nos impide estudiar, analizar y comprender las sociedades que los protagonizaron, los procesos históricos en los que se insertaban y el contexto económico que los enmarcaba. De hecho, pensamos que es más peligroso acercarse al estudio de estos acontecimientos a partir de identificaciones erróneas de lugares que reconocer que, a día de hoy, nos resulta imposible conocer con certeza su ubicación. Por ello, en este artículo nos proponemos revisar los casos concretos de tres yacimientos de la provincia de Soria que se han identificado durante el último siglo con diferentes ciudades indígenas y romanas sin tener, en ocasiones, los suficientes argumentos para ello.

Las distancias entre los oppida de la provincia de Soria varían notablemente. En el norte del Alto Duero y el noreste de la provincia encontramos ciudades-estado separadas por alrededor de $15 \mathrm{~km}$, mientras que en el sur pueden alcanzar los $30 \mathrm{~km}$ de distancia (Liceras, 20I7: 294-297). Además de a razones geográficas, es probable que esto responda a un conocimiento aún parcial sobre la ordenación del territorio durante el periodo Celtibérico Tardío. En cualquier caso, estas separaciones medias concuerdan con las documentadas en el norte de Guadalajara, en los valles y parameras del Alto Tajuña y Alto Henares, donde los oppida distan entre sí entre I2 y $25 \mathrm{~km}$.

La provincia de Soria tiene una superficie total de I0 $306,42 \mathrm{~km}^{2}$; si consideramos su superficie y las distancias medias citadas de separación entre las ciudades indígenas, podríamos proponer la existencia de entre 15 y 35 oppida en su territorio ${ }^{1}$. Se trata solamente de una proyección teórica que enmarca los siguientes epígrafes, en la que no consideramos variables geográficas ni cronológicas, bien analizadas en estudios recientes sobre el poblamiento celtibérico en el Alto Duero y en las Tierras Altas de Soria (Liceras Garrido, 20I7; Alfaro Peña, 20I8). De todos ellos se han localizado, con diverso grado de conocimiento, once, a los que se podría añadir el ubicado en torno al municipio actual de Medinaceli y la tardía ciudad de Muro, identificada tradicionalmente con Augustóbriga (figura I). Para ellos se han propuesto diferentes nombres de ciudades indígenas. Sin embargo, solamente podemos aceptar sin reticencias tres de ellos: Uxama Argaela, Termes y Numancia; a pesar de que en demasiadas ocasiones se hayan dado por seguros otras identificaciones que creemos que están realizadas sin estar sustentadas por datos suficientes:

- Ruinas Ciclópeas de Santa María de Huerta: ¿Arcobriga?

- Las Quintanas-La Cuesta del Moro de Langa de Duero: ¿Segontia Lanka?

- Medinaceli: ¿̨Ocilis, Cortona, Segontia?

- Muro/Augustobriga: ¿̇Arekorata?

Además, a través del estudio de las fuentes clásicas y de las cecas celtibéricas, se ha propuesto ubicar otros oppida en la provincia soriana sin especificar su localización concreta o señalándola sin tener base arqueológica para ello: Lagni, Malia, Lutia, Ekualakos, Veluca, etc.

1 Numero de oppida aproximado calculado a partir de distancias medias hipotéticas entre ciudades de 30 y $19 \mathrm{~km}$ respectivamente. 


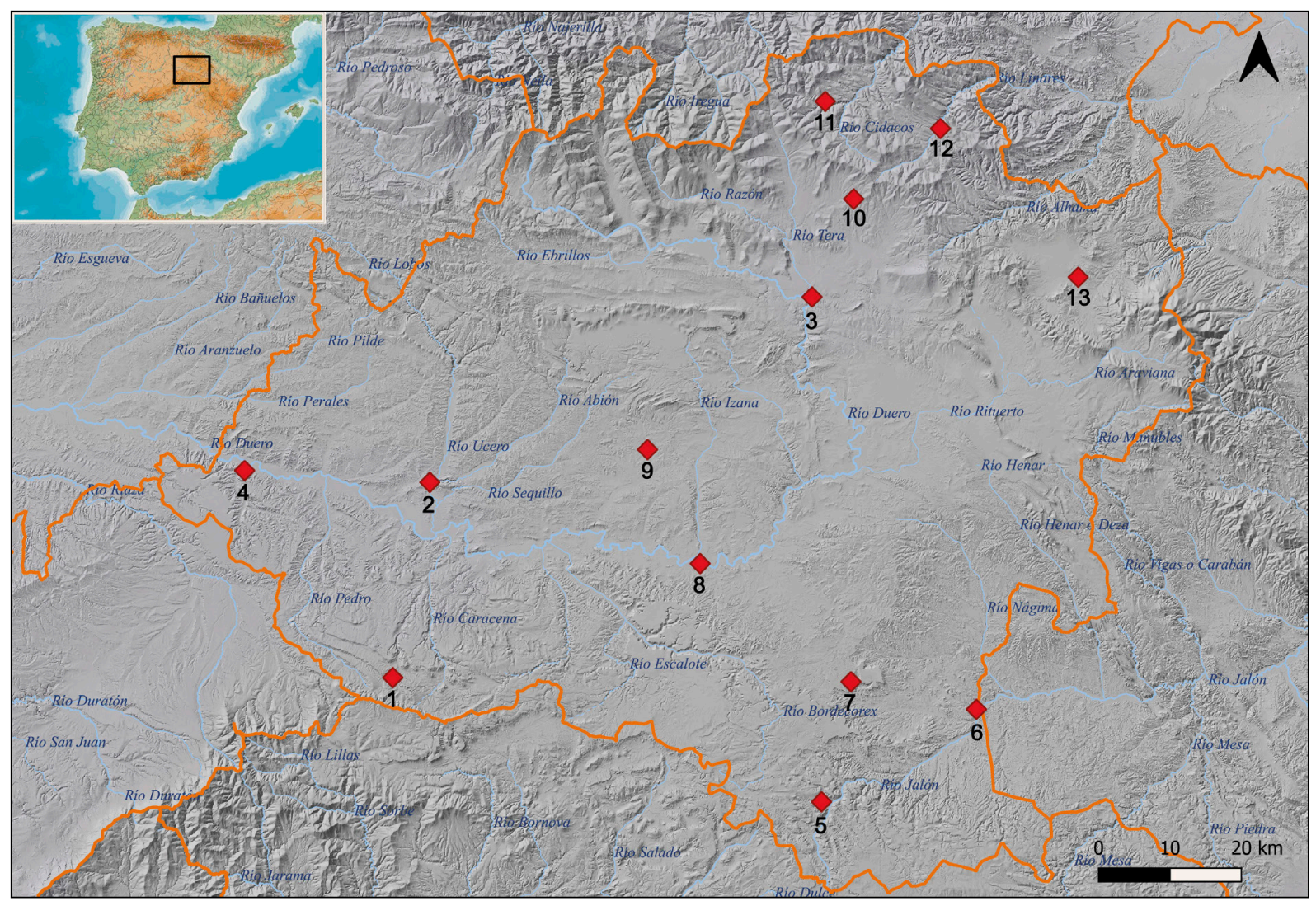

Figura 1. Oppida localizados en la provincia de Soria: 1. Termes; 2. Uxama Argaela; 3. Numancia; 4. Las Quintanas-La Cuesta del Moro (Langa de Duero); 5. ¿Medinaceli?; 6. Ruinas Ciclópeas (Santa María de Huerta); 7. El Villar (Aguaviva de la Vega); 8. Las Eras (Ciadueña); 9. Altillo de las Viñas (Ventosa de Fuentepinilla); 10. Los Villares (Ventosa de la Sierra); 11. El Castillo (La Laguna); 12. Los Casares (San Pedro Manrique); 13. Muro/Augustobriga

Figure 1. Oppida located in the province of Soria: 1. Termes; 2. Uxama Argaela; 3. Numancia; 4. Las Quintanas-La Cuesta del Moro (Langa de Duero); 5. Medinaceli?; 6. Ruinas Ciclópeas (Santa María de Huerta); 7. El Villar (Aguaviva de la Vega); 8. Las Eras (Ciadueña); 9. Altillo de las Viñas (Ventosa de Fuentepinilla); 10. Los Villares (Ventosa de la Sierra); 11. El Castillo (La Laguna); 12. Los Casares (San Pedro Manrique); 13. Muro/Augustobriga

\section{Las Ruinas Ciclópeas de Santa María de Huerta y Granja de San Pedro}

El yacimiento de las Ruinas Ciclópeas está situado en las localidades de Santa María de Huerta (Soria) y Granja de San Pedro (Zaragoza) a caballo entre las comunidades autónomas de Castilla y León y Aragón ${ }^{2}$. Se ubica en el extremo meridional y en la ladera sur de un largo espolón que conecta con los páramos de la cuenca de Almazán (figuras 2 y 4).

El yacimiento fue dado a conocer por Enrique de Aguilera y Gamboa, marqués de Cerralbo, en el año 1909 en su obra El Alto Jalón. Descubrimientos

2 Ha recibido diferentes topónimos desde que fue dado a conocer por el marqués de Cerralbo en 1909 . arqueológicos. Cerralbo financió la excavación de sus importantes fortificaciones y de parte de los espacios domésticos de las plataformas superiores del cerro (figura 3). Recientemente, entre los años 2005 a 20I2, con motivo de las obras de conservación y explotación de la autovía A-2, se llevó a cabo la prospección intensiva del yacimiento y pequeñas excavaciones en su falda sur que permitieron documentar varios espacios domésticos muy alterados. Los resultados de esta intervención, junto con una profunda descripción y análisis del yacimiento han sido publicados por Rodríguez Cifuentes (2014: 250-285). Las Ruinas Ciclópeas, con una superficie de entre 2,5 y 5 hectáreas, ocupan las plataformas meridionales del espolón y gran parte de su ladera sur, hasta el comienzo de la vega. En su lado norte presenta imponentes fortificaciones que cortan su acceso natural 


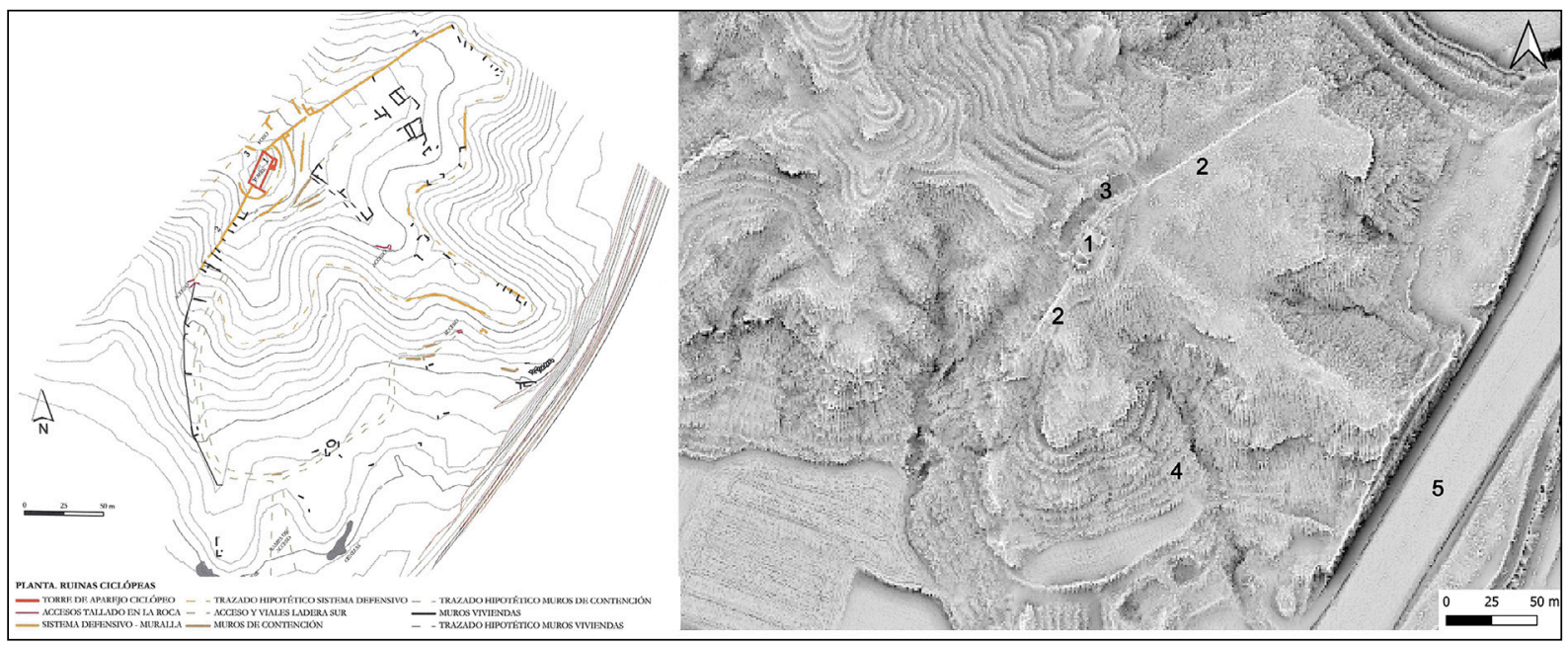

Figura 2. Modelo digital LiDAR del yacimiento de las Ruinas Ciclópeas: 1. Fortaleza; 2. Murallas; 3. Fosos; 4. Ladera sur; 5. Autovía A-2

Figure 2. LiDAR digital model of the the Ruinas Ciclópeas site: 1. Fortress; 2. Ramparts; 3. Moats; 4. South hillside; 5 . Highway A-2

desde el páramo: dos fosos, fortaleza de sillares ciclópeos y murallas que se adosan a ella (Aguilera y Gamboa, I909: 6I-70) (figuras 2 y 4) ? $^{3}$. Rodríguez Cifuentes aboga por estructurar el desarrollo del poblado de las Ruinas Ciclópeas en tres fases sucesivas (20I4: 28I-285). En una primera, anterior al siglo in a. C., se construiría la fortaleza ciclópea con el objetivo de servir de punto de control del territorio. Posteriormente, en el siglo III, surgiría el poblado, al excavarse los fosos y erigirse los dos lienzos defensivos principales y, quizá, otros menores que cerrarían el acceso desde el Jalón. Durante esta etapa

3 La protección del acceso natural a las Ruinas Ciclópeas responde a un esquema básico de defensa en barrera. Este modelo de fortificación está presente en el Alto Tajuña-Alto Jalón desde fechas muy tempranas, como muestra el pequeño poblado de El Sargal de Renales, datado en el siglo viı a. C. Sin embargo, durante la Segunda Edad del Hierro alcanza gran complejidad al anteponer a las murallas fosos y fortalezas. De los muchos ejemplos existentes sirva el de El Castillar de Navalpotro-E1 Sotillo en el Alto Tajuña, un pequeño enclave de media hectárea defendido por un foso, una imponente fortaleza de planta semicircular, construida con grandes bloques calizos, que conserva una altura máxima superior a los cuatro metros y dos tramos rectilíneos de muralla sin elementos de flanqueo que parten de la fortaleza. Los materiales recuperados en la prospección intensiva del yacimiento, una treintena de bordes moldurados y de «cabeza de ánade», permiten proponer su construcción entre finales del siglo $\mathrm{v}$ y las primeras décadas del siglo III a. C. en consonancia con el surgimiento del cercano oppidum de La Torresaviñán, en cuya necrópolis Cerralbo excavó entre 2000 y 3000 sepulturas en I9I4 y I9I6. las viviendas se concentrarían en las plataformas superiores del cerro. Finalmente, en la charnela de los siglos III-II a. C., las viviendas rebasarían el recinto defensivo expandiéndose por la ladera sur hasta casi alcanzar la vega. Ante la ausencia de restos de cerámica de importación, el autor propone que el hábitat no alcanzaría la segunda mitad del citado siglo, abandonándose sin que mediase fin violento, pues no se han documentado niveles de destrucción (Rodríguez Cifuentes, 20I4: 284). Con esta cronología para el abandono del poblado coincide también Gonzalo Monge (20I4: 45), quien realizó la prospección intensiva del yacimiento en 2005 .

En el entorno inmediato de las Ruinas Ciclópeas se documentan otros dos yacimientos adscribibles al Celtibérico Tardío, ubicados ambos en el municipio zaragozano de Monreal de Ariza (figura 5). Tres kilómetros al este, en la margen derecha del Jalón, se localiza el Cerro Villar. Este emplazamiento presenta una amplia secuencia de ocupación que incluye materiales de la Primera y de la Segunda Edad del Hierro, además de los restos de un núcleo urbano romano. De entre los materiales celtibéricos destacan por su abundancia los adscribibles a los siglos III-I a. C., que deben vincularse con la cercana necrópolis excavada por Cerralbo (Lorrio y Sánchez de Prado, 2009: 489). Sin embargo, al tratarse de materiales descontextualizados es complicado establecer la entidad real de la ocupación celtibérica del cerro. A 500 metros al noroeste del 


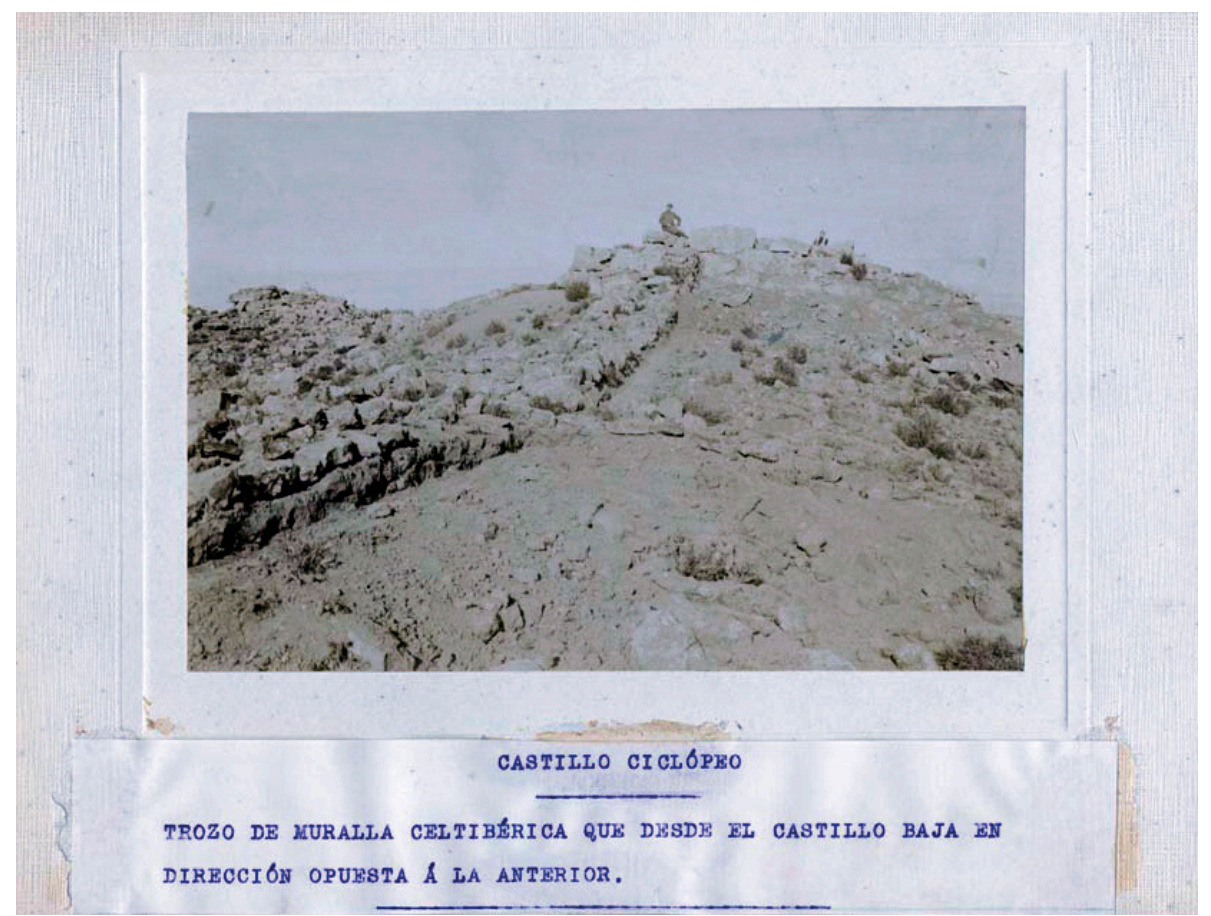

Figura 3. Fortificaciones de las Ruinas Ciclópeas durante las excavaciones del marqués de Cerralbo en la segunda década del siglo XX (fotografía original y digitalización: Juan Cabré Aguiló, Ángel Martínez Levas, Museo Cerralbo, Madrid. OHerederos de Juan Cabré Aguiló)

Figure 3. Fortifications of the Ruinas Ciclópeas during the excavations of the Marquis of Cerralbo in the second decade of the $20^{\text {th }}$ century (original photograph and digitization: Juan Cabré Aguiló, Ángel Martínez Levas, Museo Cerralbo, Madrid. (CHerederos de Juan Cabré Aguiló)

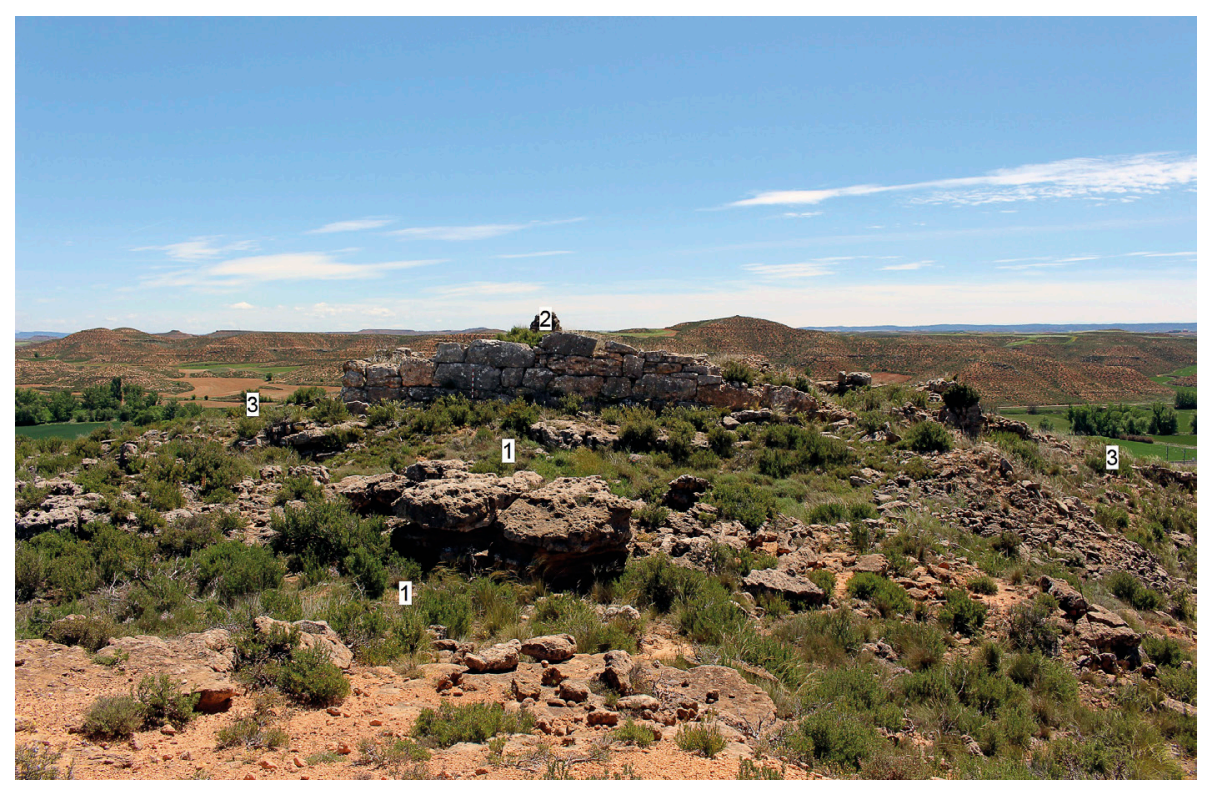

Figura 4. Vista exterior de las Ruinas Ciclópeas: 1. Fosos; 2. Fortaleza; 3. Murallas

Figure 4. View of the Ruinas Ciclópeas site: 1. Ditches; 2. Fortress; 3. Ramparts

Cerro Villar se ubica otro yacimiento de la Segunda Edad del Hierro denominado Vallunquer. A pesar de que se ha propuesto que podría tratarse de un asentamiento con unas dimensiones de alrededor de 3 hectáreas (Caballero, 1996: 46), estudios más recientes parecen limitarlo a un pequeño poblado fortificado en espolón (Royo Guillen y Gómez Legumberri, 2005-2006: 3II). 


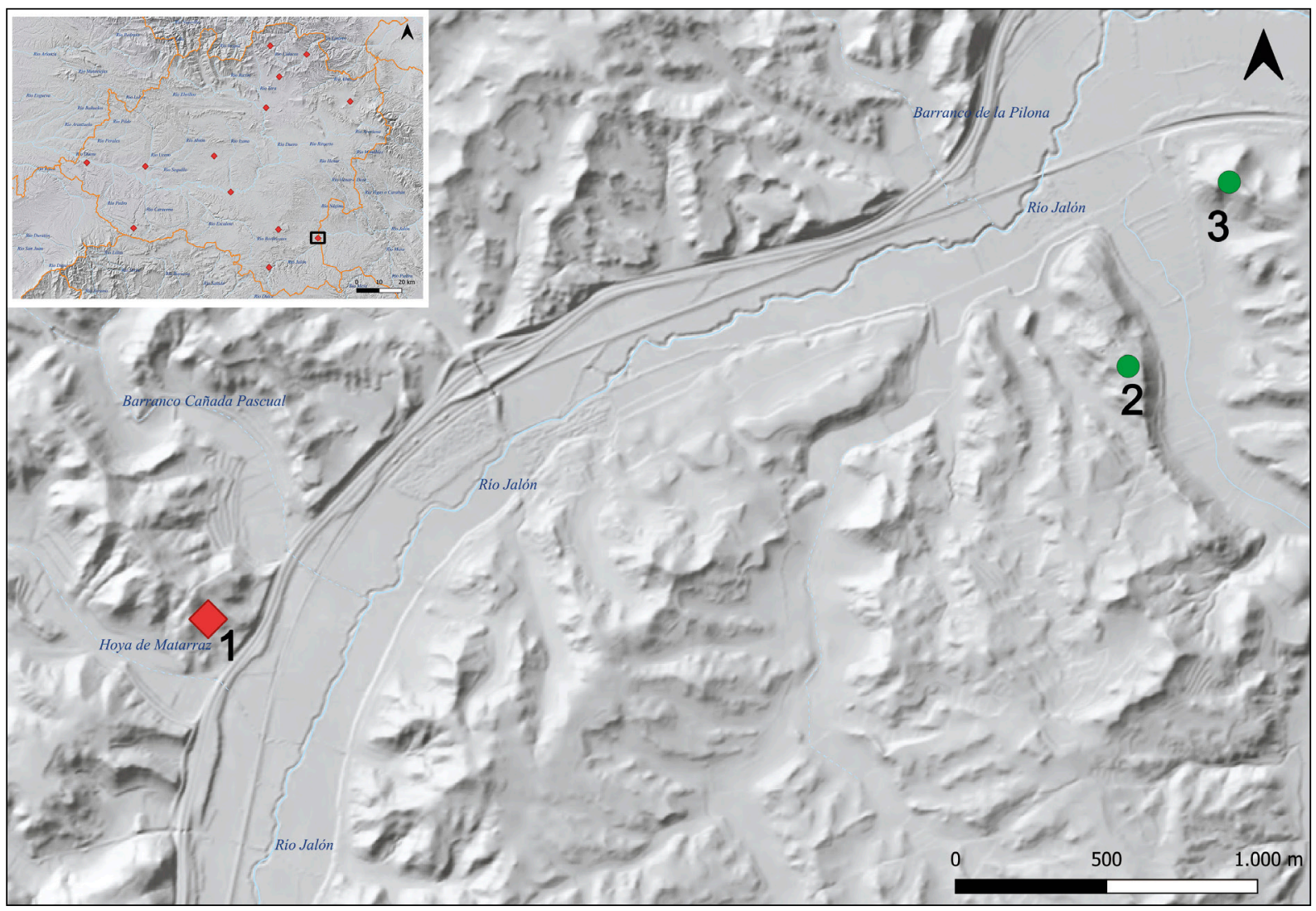

Figura 5. Poblados de la Segunda Edad del Hierro en el entorno de las Ruinas Ciclópeas: 1. Ruinas Ciclópeas (Santa María de Huerta-Granja de San Pedro); 2. Cerro Villar (Monreal de Ariza); 3. Vallunquer (Monreal de Ariza)

Figure 5. Settlements of the Second Iron Age in the surroundings of the Ruinas Ciclópeas: 1. Ruinas Ciclópeas (Santa María de Huerta-Granja de San Pedro); 2. Cerro Villar (Monreal de Ariza); 3. Vallunquer (Monreal de Ariza)

\subsection{La ciudad indígena y romana de Arcobriga}

Las fuentes griegas y romanas no citan la ciudad de Arcobriga en las campañas militares romanas en Celtiberia. Tampoco ha sido identificada como ceca emisora de moneda. Por tanto, las únicas referencias bibliográficas, documentales y epigráficas que tenemos de ella son las siguientes:

- Plinio cita a los arcobrigenses como un pueblo tributario del convento Caesarugustano (Plinio: 3, 24).

- Ptolomeo cita a Arcobriga como ciudad de los celtíberos (Ptolomeo: 2, 6, 58).

- E1 Itinerario de Antonino recoge en sus rutas 24, 25, 26 y 29, de acuerdo a la tradicional numeración de Saaavedra, la mansio Arcobriga entre las de Segontia y Aquae Bilbilitanorum.

- El Anónimo de Rávena recoge igualmente esta mansio en un trazado de vía equivalente.
- Dos inscripciones sobre piedra procedentes de Maguncia (Alemania) y Guadalajara citan también esta ciudad (Gamo, 20I8: 3II).

- Tésera de hospitalidad de latón con forma de delfín de $5,7 \mathrm{~cm}$ de longitud. Presenta una inscripción en lengua celtibérica y alfabeto latino escrita mediante punción (Jordán, 2019: 865). La traducción parcial de la misma según este autor sería «Pacto de Arcobriga...» (Ibidem: 867). La pieza, perteneciente a la colección Cerralbo se conserva en el Museo Arqueológico Nacional desde 2orI, y ha sido datada por el Departamento de Protohistoria y Colonizaciones en el siglo i a. C. ${ }^{4}$. Más adelante volveremos sobre esta tésera.

La fuente a la que se ha recurrido tradicionalmente para ubicar Arcobriga ha sido el Itinerario

4 Número de inventario 2007/55/6. 
Antonino. A pesar de que existen diferentes propuestas para el trazado de la vía entre Bilbilis y Complutum $^{5}$, la mayor parte de los investigadores coinciden en llevarla por el valle del Jalón y posteriormente por el del Henares. De acuerdo con este trazado, la ubicación de la ciudad romana de Arcobriga ha variado entre la localidad de Arcos de Jalón (Soria) y el Cerro Villar de Monreal de Ariza (Zaragoza $)^{6}$. En 1909 Cerralbo rechazó la tradicional identificación de Arcobriga con Arcos de Jalón y propuso su localización en el yacimiento aragonés (Aguilera y Gamboa, 1909: I06-IIo). Sin embargo, esta hipótesis no se ha impuesto entre los investigadores hasta las últimas décadas, siendo actualmente aceptada casi de forma unánime (Lostal, 1976; Burillo, 2008: 24r; Lorrio y Sánchez de Prado, 2009; Gamo, 20I8: 3II). Los argumentos para aceptar la situación de la Arcobriga romana en el Cerro Villar de Monreal de Ariza son fundamentalmente la existencia en este emplazamiento de un yacimiento imperial romano de características urbanas, frente a la ausencia de restos romanos de entidad en Arcos de Jalón, y la coincidencia de las distancias citadas en el Itinerario Antonino con las existentes entre el yacimiento del Cerro de la Bámbola de Calatayud y el Cerro Villar. Respecto a la tésera de hospitalidad a la que nos hemos referido anteriormente, no debe valorarse como argumento concluyente para ubicar Arcobriga (Beltrán, 2004: 70). En primer lugar, porque al tratarse de una tésera de hospitalidad, su hallazgo en un determinado yacimiento no implica que el topónimo que contiene deba reducirse a dicho yacimiento pues, lógicamente, pudo ser desplazada por su propietario hasta otra ubicación. Además, en el caso concreto de la tésera de Arcobriga su procedencia puede resultar algo dudosa. Como recogen Torija y Baquedano en el artículo que en 2007 dio a conocer el redescubrimiento de la tésera, la primera referencia a la misma procede de una necrológica de Cerralbo que publicó Juan Cabré en la revista

5 Para las diferentes propuestas ver Caballero, 20I6: 30I-305; y Aguilera y Gamboa, I909: 7-Io.

6 Juan de Mariana, siglos antes, había ubicado Arcobriga en la cercana localidad aragonesa de Ariza (Taracena, I94I: 38). semanal Ibérica. El progreso de las ciencias y sus aplicaciones en $1922^{7}$ :

La Ciudad ibero-romana de Arcóbriga [...] constituía uno de los grandes ideales y entusiasmos del marqués de Cerralbo, y en su atribución estuvo interesado su amor propio, porque ciertos arqueólogos de mucho renombre, de gabinete más que de campo, se obstinaban en fijar la Arcóbriga del Itinerario Antonino [...], en Arcos, ateniéndose a la concordancia etimológica y más aún, a una inscripción romana que publicó Morales, dada por falsa por Hübner. Este pleito científico se resolvió en 1920 , a favor de nuestro ilustre prócer, descubriendo en las ruinas de dicha ciudad una tésera de bronce $[. .$.$] en la que consta grabado el nombre$ geográfico de Arcóbriga» (Cabré, 1922: 316).

Esta tésera figura en varias fotografías del archivo fotográfico del Museo Cerralbo sin que explícitamente se especifique su procedencia del Cerro Villar o de su necrópolis, aunque parece estar asociado a materiales de dichos yacimientos ${ }^{8}$. Por otra parte, Cabré,en el volumen tres del Catálogo Monumental de Soria, recoge la noticia del hallazgo de una tésera en la localidad de Retortillo de Soria, sin aportar información gráfica sobre la misma (Taracena, 194r: I43; Alfayé, 2003: 9-I2). Señala: «Dicho anillo fue a poder del sr. Marqués de Cerralbo, así como de otro lugar de Retortillo una lámina de bronce de unos 5 centímetros representando un delfín el cual tenía grabado en uno de sus lados una inscripción con caracteres romanos» (Cabré, 19I7: II4 y II5), presentando, por tanto, grandes similitudes descriptivas con la

7 Las autoras señalan que también es citada en una carta de Cabré a Cerralbo fechada el I3 de octubre de I920, en la que no se indica el lugar del hallazgo de la tésera. Además, también es recogida en el inventario de los materiales de la colección arqueológica de Cerralbo que redactó Cabré tras el fallecimiento del marqués: «No ${ }_{527}$-Tesera de Bronce, en forma de delfín, con inscripción en caracteres latinos donde se lee Arcóbriga. Procede de Arcóbriga (ciudad). Mide $70 \mathrm{c} / \mathrm{m}$. de long». Es evidente que el desmesurado tamaño es consecuencia de un error de transcripción.

8 Agradecemos a Rebeca Recio el acceso al fondo fotográfico del Museo Cerralbo y los comentarios acerca de estas fotografías. 
tésera de Arcobriga. La tésera de Retortillo, sin embargo, no se encuentra recogida en el inventario de la colección arqueológica Cerralbo escrito por Cabré. La existencia de dos téseras similares en una misma colección arqueológica, y el hecho de que de una de ellas no exista documentación gráfica y se desconozca su paradero, nos genera ciertas dudas.

Como hemos señalado, dejando a un lado el debate sobre el origen de la tésera, actualmente se acepta de forma prácticamente unánime la ubicación de la ciudad romana de Arcobriga en el Cerro Villar de Monreal de Ariza; sin embargo, sigue existiendo un profundo debate sobre la localización del oppidum celtibérico que la debió de preceder. Una vez rechazado el carácter urbano del cerro de Vallunquer, nos encontramos con la problemática de la existencia de dos yacimientos relevantes separados por tres kilómetros: las Ruinas Ciclópeas, asentamiento de claras características urbanas abandonado, probablemente, en un momento indeterminado del siglo iI a. C.; el Cerro Villar, con unas dimensiones desconocidas para el hábitat anterior al siglo i a. C., pero probablemente ya de importancia notable en ese siglo a juzgar por las abundantes cerámicas tardías celtibéricas (Lorrio y Sánchez de Prado, 2009: 472) y los restos de cerámica campaniense (Gonzalo, 2016: 435).

En los últimos quince años, y a falta de poder concretar las dimensiones del asentamiento prerromano del Cerro Villar, se han propuesto dos teorías contrapuestas con respecto al origen de la ciudad romana de Arcobriga. Por una parte, Rodríguez Cifuentes y Gonzalo Monge coinciden en resaltar la relevancia del yacimiento de las Ruinas Ciclópeas en los siglos iII y iı a. C., proponiendo el primero un traslado de su población a finales del siglo II o comienzos del i a. C. al Cerro Villar (Rodríguez Cifuentes, 20I4: 284 y 285; Gonzalo, 20I4 y 20I6). Lorrio y Sánchez de Prado proponen, en cambio, que los materiales documentados en el Cerro Villar vinculan este yacimiento con la necrópolis excavada por Cerralbo a la que otorgan un uso que se extiende desde finales del siglo iv al i a. C. (Lorrio y Sánchez de Prado, 2009: 496). Además, señalan que el conjunto epigráfico en lengua celtibérica hallado en el Cerro Villar compuesto por una fusayola, varios pondera, una pesa de bronce, dos fragmentos cerámicos y dos téseras zoomorfas, entre las que incluyen la del delfín, «[...] puede ser considerado como un indicio, a nuestro juicio, determinante, del carácter urbano de este enclave que cabe identificar con la ciudad de Arcóbriga» (Ibidem: 485). Concluyen afirmando que sería un caso equiparable a los de Uxama y Termes, en los que desde un núcleo antiguo surge primero una ciudad celtibérica que evoluciona, posteriormente, a una ciudad romana altoimperial (Ibídem: 489). Creemos que los argumentos de Lorrio y Sánchez de Prado pueden ser válidos para situar en el Cerro Villar un núcleo urbano, al menos, en el siglo i a. C. A pesar de ello, hay que señalar que los conjuntos epigráficos indígenas pueden proceder también de asentamientos menores como demuestran casos como los de la Necrópolis de la Yunta o el Pinar de Chera, ambos en Guadalajara (Gamo, 20I4: 68-68 y I03-II8). Hay que recordar que nos encontramos ante ciudades-estado de características rurales, en las que los ciudadanos residen tanto en la ciudad como en las aldeas (Burillo, 20Ir: 288 y 289).

En conclusión, creemos que la propuesta de Rodríguez Cifuentes y Gonzalo no es totalmente incompatible con la de Lorrio y Sánchez de Prado. Así, desde finales del siglo iv o comienzos del iı a. C., existiría una pequeña ciudad-estado, cuyo centro urbano estaría ubicado en las Ruinas Ciclópeas de Santa María de Huerta-Granja de San Pedro, en cuyo territorio se diseminarían diferentes aldeas, entre las que podría identificarse el Cerro Villar. En un momento indeterminado de la segunda mitad del siglo II o comienzos del siglo i, la población de este oppidum se trasladaría al Cerro Villar de Monreal de Ariza que terminaría por englobar el territorio de diferentes oppida indígenas y daría lugar a la ciudad celtíbero-romana de Arcobriga, citada en la tésera del delfín y a la ciudad altoimperial recogida en las obras de Plinio y Ptolomeo y en el Itinerario de Antonino.

Es más aventurado identificar el topónimo del oppidum de las Ruinas ciclópeas. Los cargos públicos romanos en el momento de fundar o refundar una nueva ciudad podían recurrir a diversas fórmulas:

- Otorgarle un nuevo nombre latino, estuviese la ciudad asentada ex nuevo, caso de Gracurris (Apiano, 43; Burillo, 2008: 280), o estuviese construida 
sobre un asentamiento indígena anterior, caso de Caesar Augusta (Plinio, III, 24).

- Otorgarle un nuevo nombre indígena latinizado o un nombre mixto: Iuliobriga, Augustobriga, etc.

- Mantener el nombre indígena, latinizándolo:

- Mantener el nombre indígena del oppidum sobre el que se asienta: Numancia, Termes, etc.

- Mantener el nombre indígena de la ciudad sobre cuyo territorio se asienta, aunque no se emplace directamente sobre ella: Segeda, en su emplazamiento en Durón de Belmonte de Gracián (Burillo, 2008: 318), Clunia Colonia, etc.

- Otorgarle el nombre indígena latinizado de una de las varias ciudades indígenas cuyo territorio absorbe o que conforma parte del contingente de población fundacional: por ser esta la más cercana a los conquistadores, la más poblada o más fuerte en cualquiera de las acepciones.

Por tanto, creemos que en el estado actual de las investigaciones no tenemos los suficientes datos que permitan conocer con certeza el nombre de la ciudad indígena ubicada en las Ruinas Ciclópeas, cuyo carácter urbano parece probable.

\section{Las Quintanas-La Cuesta del Moro (Langa de Duero)}

El yacimiento de Las Quintanas-La Cuesta del Moro se ubica en una zona de fuerte desnivel en la margen izquierda del río Duero, junto a la desembocadura del arroyo de Valdanzo (figuras 6 y 7 ). Se localiza en un terreno de ladera que desciende desde el páramo a la vega del río, a través de fuertes desniveles, espigones calizos, y laderas más tendidas (Tabernero, 2017: 93).

Los estudios del lugar comenzaron en 1928 gracias a la labor de Blas de Taracena. Este arqueólogo realizó dos campañas en el yacimiento en las décadas de 1920 y 1930, en las que excavó $5450 \mathrm{~m}^{2}$ ( $\mathrm{Ta}$ racena, I929 y 1932: 52-6I). Posteriormente, en 1992 se realizó una prospección intensiva del yacimiento y de su entorno inmediato que documentó restos arqueológicos en un área de 75 hectáreas, y tres pequeños sondeos estratigráficos, excavándose un total de $15 \mathrm{~m}^{2}$ (Tabernero et alii, 2005: 197-204). Finalmente, en 1999 y 2002 se realizaron cuatro nuevos sondeos (ibidem: 200) (figura 7$)^{9}$.

Tabernero (2017: 106 y 107) propone dos fases de ocupación de la ciudad indígena. Una primera, circunscrita a la zona de Las Quintanas y una segunda que, desde este lugar, se extiende hacia la «zona sur» y la Cuesta del Moro (figuras 6 y 7 ) $^{10}$. La primera se correspondería con la fase de fundación de la ciudad que, al menos, se remonta a comienzos del siglo II a. C. El oppidum tendría un urbanismo denso condicionado por la topografía, extendiéndose por una superficie estimada de $\mathrm{I} 4$ hectáreas, delimitadas por muralla y foso. La segunda fase comienza a finales del siglo II y, en opinión del autor, se extiende durante todo el siglo i a. C. Durante este periodo el poblamiento se expande a una superficie mayor, aunque no toda ella sería apta para la construcción, por presentar fuertes desniveles y escarpes rocosos. Esta segunda fase es la mejor representada, pues su desarrollo habría supuesto el desmantelamiento y arrasamiento de la fase anterior en la mayor parte del yacimiento ${ }^{11}$.

El momento de abandono de la ciudad indígena es impreciso, no superando, en cualquier caso, el cambio de era (Tabernero: 20I7, I07; Tabernero, et alii: 2005, 202). Esto lo explican atendiendo a la ausencia de emisiones monetarias de la segunda mitad del siglo i a. C.; la ausencia de sigillata entre los materiales documentados en los sondeos; la presencia de tres fragmentos de cerámica campaniense, un fragmento de un ánfora Dressel 1B, y diversos fragmentos de dolia tipo Ilduratin; presencia de fibulas en

9 Un plano detallado de la topografía del yacimiento, sus diferentes zonas, la ubicación de los sondeos modernos y la propuesta de ubicación de las excavaciones de Taracena, que no se conoce con exactitud, en Tabernero, 20I7: fig. I.

10 En este esquema de desarrollo urbano quedan sin analizar los hallazgos de cerámica a torno celtibérica en el Cerro Moro, que no pueden explicarse por procesos erosivos, al estar situados en una cota superior al resto del yacimiento. Desde nuestro punto de vista sería más ortodoxo un desarrollo de la ciudad desde este emplazamiento en altura hacia las cotas menos elevadas de la ladera del páramo, que a la inversa. 11 Existen algunas excepciones como los dos niveles de ocupación superpuestos localizados en la vivienda 5 de la Cuesta del Moro (Taracena, I932: 52 y 53) y en el sondeo realizado en 1999 en las Quintanas (Tabernero et alii, 2005). 


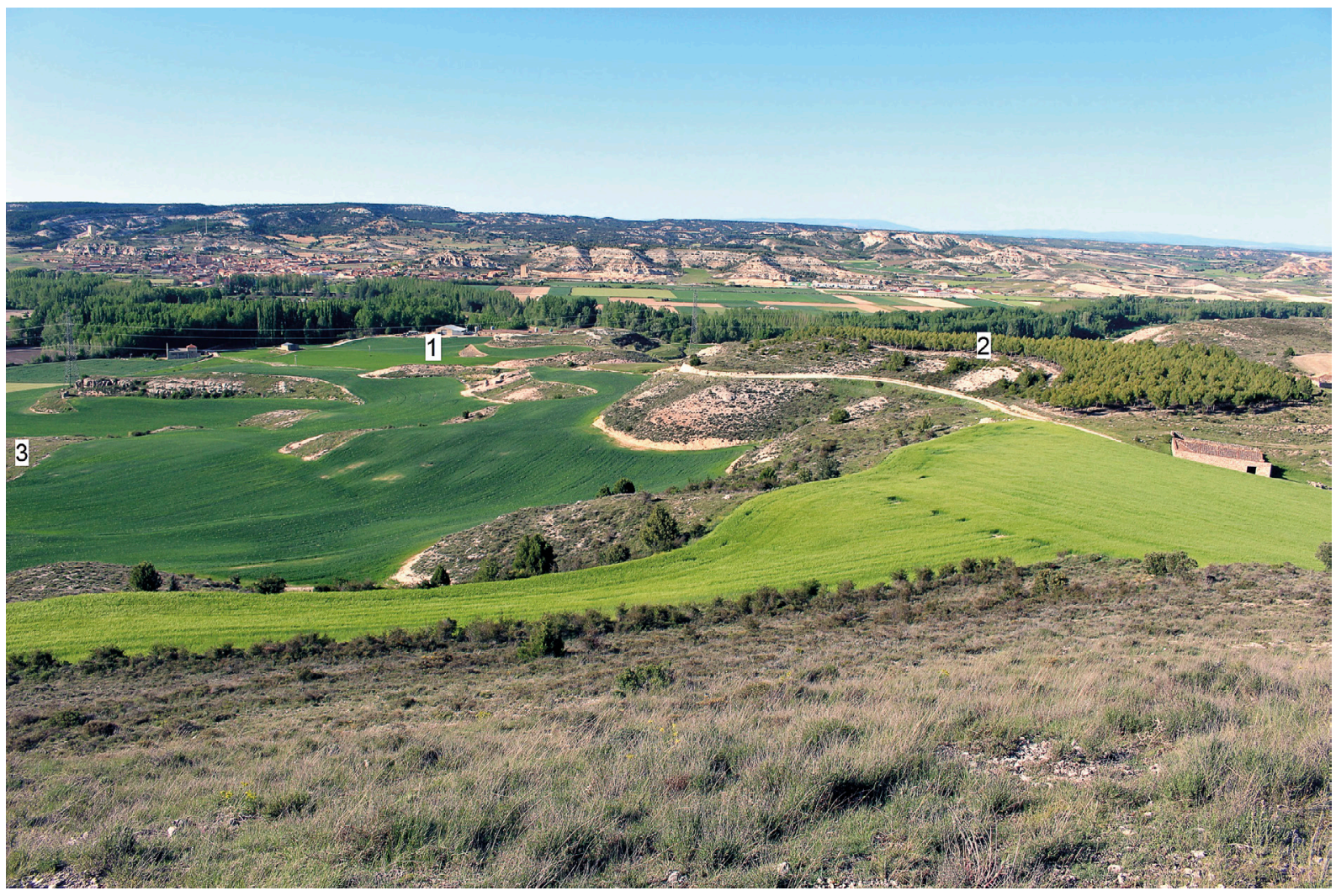

Figura 6. Vista del yacimiento desde Cerro Moro: 1. Las Quintanas; 2. La Cuesta del Moro; 3. Zona sur

Figure 6. View of the site from Cerro Moro: 1. Las Quintanas; 2. La Cuesta del Moro; 3. South Zone

omega; y una fecha de una muestra de madera procedente de una viga carbonizada, datada con ${ }^{14} \mathrm{C}$ a dos sigmas con un $98 \%$ de probabilidad entre el 165 a. C. y el 28 d. C. ${ }^{12}$. Sin embargo, creemos que se puede precisar más el momento de abandono de la ciudad. Los restos recuperados en las diversas campañas arqueológicas y, especialmente, los recogidos en las dos grandes excavaciones realizadas por Taracena, presentan notables similitudes con materiales de contextos vinculados a abandonos y destrucciones de las guerras civiles republicanas de la primera mitad del siglo I a. C. tales como los campamentos romanos de Cáceres el Viejo y de La Cerca de Aguilar de Anguita o el yacimiento de Los Rodiles de Cubillejo de la Sierra, por poner algunos ejemplos. En este sentido apuntarían los objetos citados en el párrafo anterior, así como el conjunto de armas que halló Taracena en los diversos espacios domésticos que excavó: soliferrea, jabalinas, pila, lanzas, espada de antenas, espada de La Tène, puñales biglobulares, conjunto de glandes de plomo, etc. ${ }^{13}$. Por tanto, creemos que es posible proponer una fecha para el abandono del oppida vinculada con las guerras de la primera mitad del siglo i a. C.

\section{1. ¿Segortia/Segontia Lanca en Langa de Duero?}

Plinio señala la utilización del Topónimo Secontia para nombrar diferentes lugares $(3,27)$. Atendiendo a ello, Gamo (2018: 304 y 305) identifica la existencia de seis segontias diferentes habitadas durante época imperial y citadas por las fuentes clásicas. Dos citadas en las vías XXIV y XXV del Itinerario Antonino, y cuatro recogidas en la Geografía de Ptolomeo: Segontia Paramica de los vacceos, Segontia Paramica de los várdulos, Saguntia de los turdetanos

13 Un inventario detallado de las armas documentadas en las excavaciones de Taracena en Quesada, 1997: 775. 


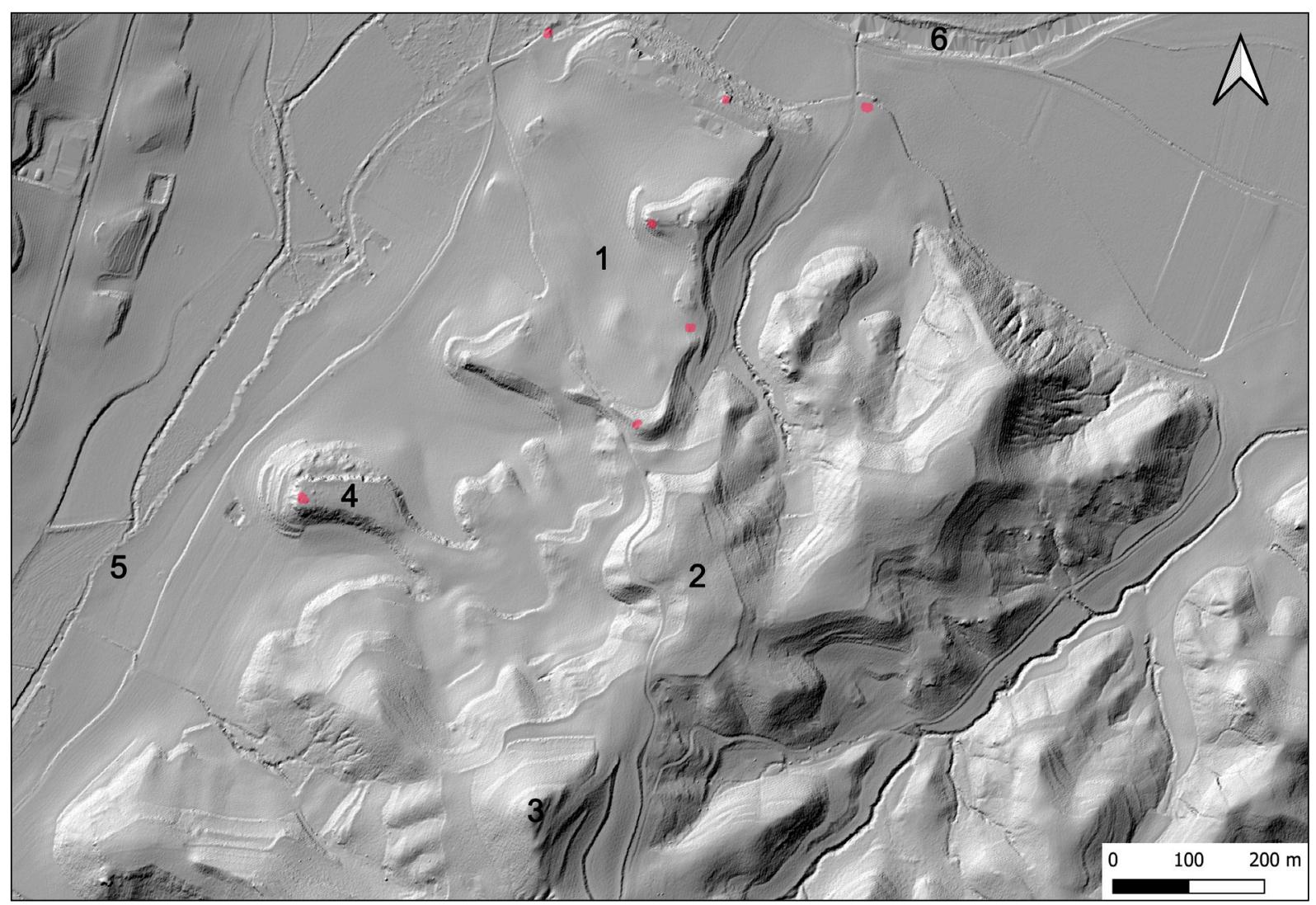

Figura 7. Modelo digital LiDAR del yacimiento de Las Quintanas-La Cuesta del Moro: 1. Las Quintanas; 2. La Cuesta del Moro; 3. Cerro Moro; 4. Zona Sur; 5. Arroyo de Valdanzo; 6. Río Duero

Figure 7. LiDAR digital model of the Las Quintanas-La Cuesta del Moro site: 1. Las Quintanas; 2. La Cuesta del Moro; 3. Cerro Moro; 4. South Zone; 5. Valdanzo stream; 6. Duero river

y Segontia Lanca de los arévacos ${ }^{14}$. Algunas de estas ciudades y, quizá, alguna otra que no pervivió en época imperial, son citadas también en las fuentes clásicas al narrar los acontecimientos bélicos que tuvieron lugar en la península ibérica durante los siglos ir y i a. C.

Debido a la similitud de los topónimos se acepta de forma generalizada la equiparación de la ciudad romana de Segortia Lanca con la ceca celtibérica Sekotias Lakas que acuñó denarios y ases en el tránsito del siglo Ir al i a. C. (García-Bellido, 20or: 348).

Blas de Taracena fue el primero en proponer la ubicación de la ciudad de Segontia Lanca en el yacimiento de Las Quintanas-La Cuesta del Moro de Langa de Duero (Taracena, I94r: 90). Justificó

14 Estas dos últimas son citadas también por Plinio en su Historia Natural en el Convento Gaditano y Cluniense respectivamente, la última es nombrada solamente por su topónimo principal: Secontia. su propuesta aludiendo a la cita de Estrabón de un lugar llamado Serguntia por el que fluye el Duero, a las referencias de Plinio y Ptolomeo y a la similitud de esta última con el nombre de la localidad actual de Langa de Duero. Como la mayor parte de sus propuestas de ubicación de ciudades celtibéricas, la identificación de Segontia Lanca ha sido generalmente aceptada (Capalvo, 1996: 71; Lorrio, 2005: 69 y Iо7; Burillo, 2008: 230; Jimeno, 20Ir: 235, 240 y 24I; Gamo, 2018: 302 y 304) ${ }^{15}$. Tabernero (2017) también apoya esta localización e identifica el yacimiento con la ceca de Sekotias Lakas. A este respecto, hemos de señalar que en el lote de monedas localizado por Taracena en Langa de Duero, compuesto

15 Con algunas excepciones. Sirva de ejemplo Gómez Fraile (200I: Io9 y IIo) quien aboga por ubicar Segontia Lanca en Sigüenza y no en Langa de Duero, atendiendo, entre otras razones, al temprano abandono del yacimiento de Langa de Duero. 
por 16 ejemplares, no hay ninguna de la ceca segontina ${ }^{16}$. Martínez Caballero (20I0) identifica también este yacimiento con la ceca señalada. Además, también localiza en su territorio la ciudad romana de Segontia Lanca al proponer la existencia de una ciudad dispersa o polinuclear.

Sin embargo, a nuestro juicio, esta hipótesis no reúne los requisitos necesarios para considerarse segura. En primer lugar, resulta extraño que el enclave conservase, no el nombre principal de la población: Segontia, sino el complemento utilizado para diferenciarla de sus homónimas: Lanca. Por otra parte, el topónimo «Langa», que derivaría del anterior, es relativamente común en la toponimia española y su origen no tiene por qué buscarse en una ciudad prerromana. Así, encontramos, además de Langa de Duero (Soria) y Languilla (Segovia) que deriva de la primera población, el municipio de Langa (Ávila), y los de Langa del Castillo (Zaragoza) y La Langa (Cuenca) ${ }^{17}$. Por otra parte, como indican las referencias de Ptolomeo y Plinio, el oppidum celtibérico continuó poblado como núcleo urbano, al menos, durante el Alto Imperio. Durante este periodo, como hemos visto, el yacimiento de Las Quintanas-La Cuesta del Moro de Langa de Duero ya estaba abandonado y en su entorno no se ha localizado ningún yacimiento que pueda identificarse con una ciudad romana, a no ser que se recurra a la hipótesis de ciudad disgregada defendida por Martínez Caballero (20ro). Por tanto, nos queda solamente la imprecisa cita de Estrabón a una Serguntia junto al río Duero y la auctoritas de Taracena como defensa de esta identificación.

Por todo ello, creemos que debe reevaluarse la ubicación de Segortia Lanca en el yacimiento de Las Quintanas-La Cuesta del Moro de Langa del Duero que, en ningún caso, puede aceptarse como segura.

16 Además de 2 denarios romanos emitidos en los años I24 y 94 a. C., se localizaron I4 monedas indígenas: 5 ases (I de Kelse, I de Tamaniu y 3 inidentificables), r semis de Kesse y 8 denarios (3 de Sekobirikes y 2 de Turiasso en un recipiente cerámico en la habitación I4, otro de Turiaso, I de Arsao y I frustro) (Taracena, I932: 6o; Tabernero, 2017: 106).

17 Quizá puedan relacionarse con la misma raíz otros topónimos habituales en poblaciones peninsulares como Langayo, Berlanga o Lancara.
En esta línea deben comenzar a valorarse otras opciones. Entre ellas, proponemos, como mera hipótesis de estudio, la de la ceca de Sekobirikes, si se acepta la propuesta de García-Bellido de situar este oppidum al norte del Sistema Central (García-Bellido, 1994). E1 desarrollo de sus emisiones monetarias se ajusta notablemente bien a las evidencias arqueológicas y a las fases de desarrollo del yacimiento que estudiamos $^{18}$

\section{Medinaceli: de Segontia a Cortona y otra vez Segontia}

La identificación del nombre de la ciudad romana ubicada bajo la localidad de Medinaceli ha generado gran controversia. A lo largo del último siglo se han propuesto tres posibles topónimos celtibéricos recogidos en las fuentes clásicas y epigráficas: Ocilis, Cortona y Segontia.

Schulten la identificó con Ocilis, citada por Apiano en las campañas de Nobilior, atendiendo a cierta similitud fonética con el nombre actual de la población: Medina-Ocilis = Medinaceli (Burillo, 2008: 199). Esta similitud, sin embargo, se ha demostrado incorrecta, pues el topónimo actual de Medinaceli deriva del nombre árabe de la población: Madinat Salim, que la vincula con la familia de origen bereber que gobernaba sus tierras desde antes del año 832 y hasta el 920 d. C. (García-Contreras, 20r4: 94).

Será Burillo (2008: 24I y 32I) quien proponga una nueva hipótesis al señalar la posible ubicación de Cortona en esta localidad, atendiendo a la supuesta localización en su entorno del Bronce de Cortona. Las referencias escritas sobre Cortona son muy escasas. Se reducen a una cita de Plinio, quien señala entre los pueblos tributarios del convento Caesaraugustano a los cortonenses (Plinio, III, 24), a una tésera de hospitalidad de autenticidad dudosa (Jordán, 2019: 562-567) y al denominado Bronce

18 A pesar de ello no se han documentado divisores de la ceca de Sekobirikes en Langa de Duero. Por otra parte, los tres denarios de Sekobirikes hallados en I932 suponen el 37,5\% de los denarios indígenas localizados en el yacimiento. 
de Cortona (Burillo, 2008: $346-348)^{19}$. Sin embargo, Cortona no es citada en la relación de ciudades romanas arévacas y celtibéricas de la obra geográfica de Ptolomeo, y tampoco es recogida en el Itinerario Antonino. Por tanto, creemos que no existe argumento alguno para aceptar la identificación de Medinaceli con Cortona. Actualmente, sin embargo, esta es la propuesta más aceptada (Gómez Fraile, 200r: 108; Martínez Caballero, 2010: 156; Gamo, 20I8: 310), aunque la aceptación que tuvo su identificación con Ocilis durante el siglo xx conlleva que todavía siga citándose, pero ya de forma residual (Lorrio, 2005: 69; García-Contreras, 2013: 65I; Jordán, 2019: 324 y 533), por último, encontramos también algunos autores que prefieren mantener cierta prudencia y no decantarse por asignar ningún nombre concreto a las ruinas de la ciudad romana de Medinaceli (Martino, 2004: 394; Jimeno, 20II: 245).

Existe una tercera propuesta que ha quedado arrinconada por las dos anteriores. El arzobispo de Toledo Rodrigo Jiménez de Rada (c. II70-I247) propuso en De rebus Hispanae y en Historiae Romanorum identificar Medinaceli con la Segontia que citaban las fuentes clásicas (De rebus: IV, XI: 30-3r; Historiae: VII: 9-Ir y X: 83-84). En el capítulo X de esta última obra, Jiménez de Rada explica el razonamiento que le conduce a tal conclusión:

\section{[...] uel Medina Celim, que creditur fuisse Segoncia} propter magnitudinem et hedificiorum uestigia que apparent [...] (Historiae Romanorum, X: 8I-86) ${ }^{20}$.

Gracias a la influencia de la obra y a la autoridad del erudito navarro la identificación de Medinaceli con Segontia tuvo notable pervivencia durante toda la Edad Media y la Edad Moderna, recogiéndose

19 Jordán, en su monografía sobre Lenguas y Epigrafías Celtibéricas, propone leer este bronce con el sistema dual, lo que le lleva a proponer la lectura "gortono», en vez de «Cortono», lo que desvincularía el bronce de la ciudad de Cortona (Jordán, 2019: 670-682).

20 «[...] o de Medina Celim, de la que se cree fue Segontia por causa de la magnitud y las ruinas de los edificios que aparecen [...]». Agradecemos a Jorge Rosales Pulido del Cuerpo Facultativo de Archiveros, la traducción del fragmento al castellano. por obras y autores tan diversos como: la Estoria de España (siglo XIII), Jerónimo Zurita (I512-I580), Juan de Mariana (1536-1623), Juan Manuel de Contreras (siglo xviII), etc. (Estoria: 93; Zurita, I600: 589 y 590; de Mariana, I854: I84; de Contreras, I754: I3).

Pastor retomó esta hipótesis en 1996 al proponer la ubicación de la mansio Segontia de las vías XXIV y XXV del Itinerario de Antonino en Medinaceli. Para explicar esta identificación se apoya en la coincidencia de las millas recogidas en el Itinerario para el trayecto entre Bilbilis y Segontia con la distancia real entre el cerro de La Bámbola de Calatayud y la actual localidad de Medinaceli. Llama también la atención sobre la escasa entidad de los restos romanos hallados hasta la fecha en Sigüenza que no permiten situar una ciudad en este lugar (Pastor, 1996: 225). Por el contrario, Gamo (2018: 308) se muestra partidario de ubicarla en Sigüenza, argumentando que la Segontia del Itinerario no debe identificarse con una ciudad sino solamente con una mansio viaria. Sin embargo, no aporta argumentos para explicar cómo esta mansio pudo llegar a transformarse en el siglo vi en sede episcopal, considerando, además, la ausencia de restos hispano-visigodos en la localidad. El último argumento de Pastor, presentado en 20I4, es la cita de varias de las referencias medievales y modernas a las que nos hemos referido anteriormente, de las cuales las más relevantes proceden de las obras del arzobispo de Toledo. Algunos investigadores han señalado que, de aceptarse la propuesta de Pastor, se descuadra la distancia en millas recogida en el Itinerario entre Segontia y Complutum (Burillo, 2008: 200). Si bien es cierto que, en caso contrario, la distancia que no concuerda es la de Segontia a Bilbilis como señala Pastor. Por otra parte, este autor es consciente de la ausencia de restos celtibéricos en Medinaceli, atendiendo a los resultados de las intervenciones arqueológicas realizadas hasta la actualidad. Como posible explicación propone la ubicación del oppidum indígena en la localidad de Miño de Medinaceli, donde sí se han documentados importantes restos de la Segunda Edad del Hierro (Pastor, 20r4: rog) (figura 8).

Recapitulando todo lo referente a Medinaceli, a lo largo del último siglo se han propuesto tres posibles topónimos para identificar la ciudad romana sobre la 

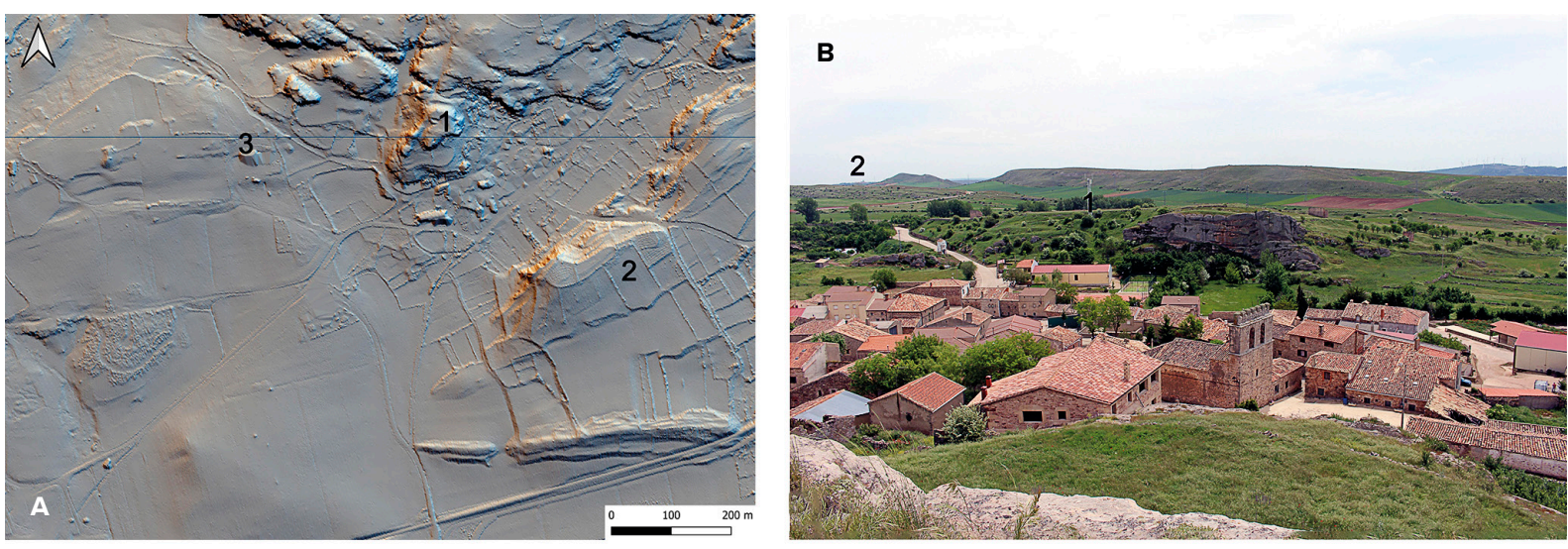

C

D
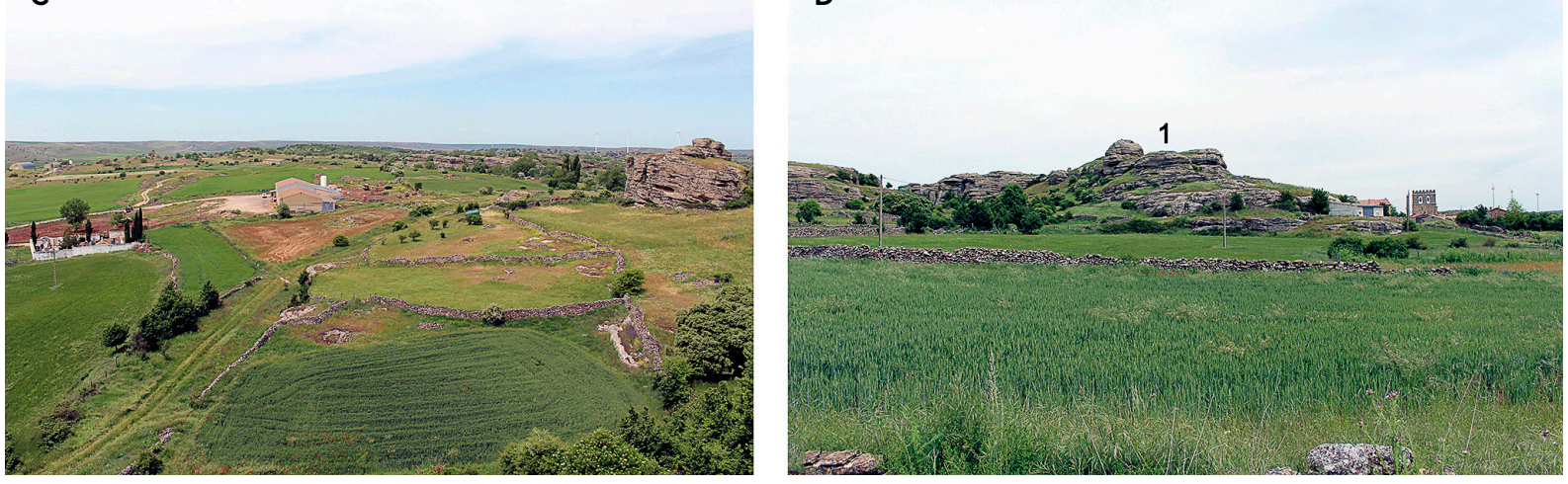

Figura 8. A. Modelo digital LiDAR de Miño de Medinaceli: 1. El Castillo; 2. La Cuesta de la Viña; 3. El Quintanar. B. Vista del yacimiento de La Cuesta de la Viña desde El Castillo: 1. La Cuesta de la Viña; 2. Medinaceli. C. Vista de El Quintanar desde El Castillo. D. Vista de El Castillo desde El Quintanar: 1. El Castillo

Figure 8. A. LiDAR digital model of the Miño de Medinaceli: 1. El Castillo; 2. La Cuesta de la Viña; 3. El Quintanar. B. View of the La Cuesta de la Viña from El Castillo: 1. La Cuesta de la Viña; 2. Medinaceli. C. View of the El Quintanar from El Castillo. D. View of the El Castillo from El Quintanar: 1. El Castillo

que se asienta: Ocilis, Cortona y Segontia. Valorando estas tres hipótesis, creemos que puede rechazarse definitivamente la primera, por los argumentos ya esgrimidos por otros autores (Burillo, 2008: 199 y 200). También debe rechazarse la segunda. En este caso no encontramos ningún indicio que permita valorarla como plausible. Por tanto, resta solamente la tercera propuesta, la que hasta la actualidad ha tenido menos impacto en los investigadores, quizá por el excesivo peso que en la historiografía reciente ha tenido la situación, a apenas 2r kilómetros de distancia, de la actual localidad de Sigüenza. Sin embargo, creemos que se trata de la hipótesis más acertada, aunque no carente de complicaciones, como es la discontinuidad del registro arqueológico entre la ciudad romana, el oppidum indígena que lo debió de preceder, y la sede episcopal hispano-visigoda que la sucedió.

Para resolver estas cuestiones creemos que es necesario realizar una revisión profunda de los materiales arqueológicos conservados en los diferentes museos con origen en el término de Medinaceli y en los municipios cercanos, procedentes tanto de las diferentes prospecciones extensivas orientadas a la realización de las Cartas Arqueológicas, como de las intervenciones de gestión y las excavaciones antiguas.

Por lo que respecta al periodo Celtibérico Tardío (350-I33 a. C.), el estudio de la organización territorial de la región del Alto Tajuña, el Alto Henares y el Alto Jalón, refleja la relativa abundancia de oppida separados por distancias que oscilan entre los I2 y los $30 \mathrm{~km}$. La existencia de ciudades indígenas rodeando Medinaceli a distancias medias de $25 \mathrm{~km}^{21}$ (figura 9), nos inducen a pensar en la necesaria existencia

21 El Castejón de Luzaga, el oppidum de La Torresaviñán, E1 Losar de El Atance, La Cabeza de Maranchel de Mazarete, El Villar de Aguaviva de la Vega y las Ruinas Ciclópeas de Santa María de Huerta y Granja de San Pedro. 


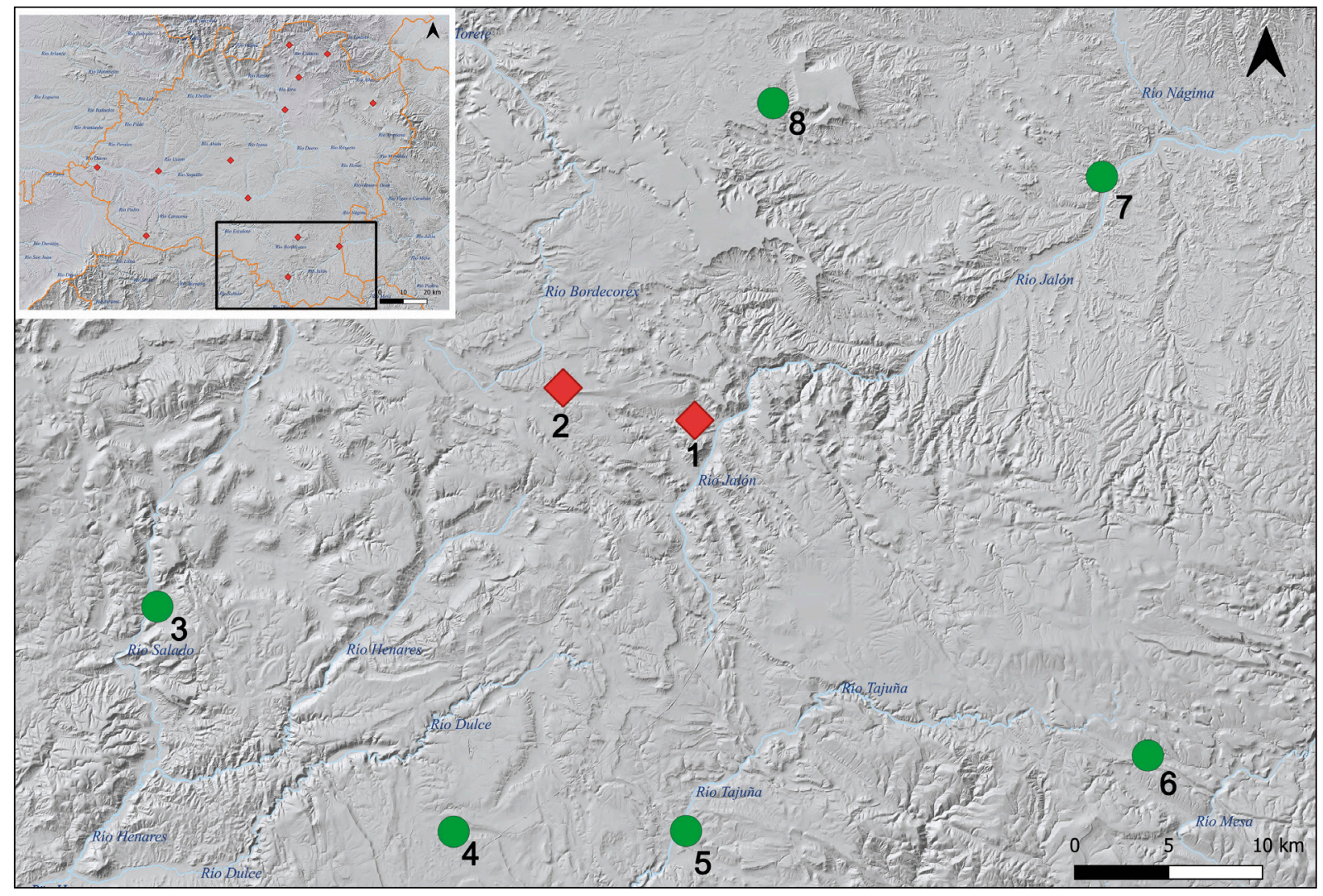

Figura 9. Oppida celtibéricos en el entorno de Medinaceli: 1. ¿Medinaceli?; 2. ¿Miño de Medinaceli?; 3. El Losar (El Atance); 4. Torresaviñán; 5. El Castejón (Luzaga); 6. Cabeza de Maranchel (Mazarete); 7. Ruinas Ciclópeas (Santa María de Huerta-Granja de San Pedro; 8. El Villar (Aguaviva de la Vega)

Figure 9. Celtiberian oppida in the surroundings of Medinaceli: 1. Medinaceli?; 2. Miño de Medinaceli?; 3. El Losar (El Atance); 4. Torresaviñán; 5. El Castejón (Luzaga); 6. Cabeza de Maranchel (Mazarete); 7. Ruinas Ciclópeas (Santa María de Huerta-Granja de San Pedro; 8. El Villar (Aguaviva de la Vega)

de un oppidum en el entorno inmediato de la localidad. A falta de la señalada revisión de materiales, es interesante valorar la propuesta de Pastor de situarlo en el cercano municipio de Miño de Medinaceli, en los yacimientos de El Castillo, La Cuesta de la Viña y El Quintanar, a menos de $7 \mathrm{~km}$ de distancia de la posterior ciudad romana (figura 8).

Por otra parte, los arqueólogos que hasta la pasada década han realizado trabajos arqueológicos en Medinaceli, han coincidido en señalar la ausencia de materiales adscribibles al periodo hispano-visigodo. Los hallazgos de esta época en su entorno son también muy escasos, más allá de la sepultura excavada por el marqués de Cerralbo en Fuencaliente de Medinaceli y las sepulturas rupestres documentadas en Miño y en Somaén. Sin embargo, es necesario valorar también algunos restos de Medinaceli poco reseñados hasta el momento. Se trata de los llamados «Cuerpos Santos», que fueron objeto de varias publicaciones destacadas a comienzos de la pasada década (De la Casa, 20I2, 20I3; De la Casa e Illarregui, 2013; Nieto, 20I2). Juan Manuel de Contreras, canónigo magistral de la colegial de Medinaceli y abad de la colegiata de Nuestra Señora del Mercado de Berlanga de Duero, publicó un estudio en I754 en el que recopilaba la información existente sobre estos restos. En su libro recoge las primeras noticias sobre la existencia de una capilla dedicada a albergar las sepulturas de cinco mártires del siglo $\mathrm{v}$ a. C. en la antigua iglesia parroquial de San Román de Medinaceli. En i58I el notario Gabriel López, por orden del visitador general del obispo de Sigüenza, levantó acta de la exhumación de los enterramientos existentes en dicha capilla. Se localizaron, al menos, cuatro cuerpos en tres sepulturas, acompañados de dos ampollas de vidrio verde y blanco, una bujética también de vidrio, restos de madera carcomida y un báculo de bronce 
con decoración incisa ${ }^{22}$, al que le faltaba la vara de madera (De Contreras, I754: 76-82) ${ }^{23}$. De la Casa, Illarregui y Nieto proponen para los objetos que acompañaban a los cuerpos unas fechas comprendidas entre el siglo v y el siglo vin d. C. a pesar de que difieren notablemente sobre su vinculación con los restos óseos (De la Casa e Illarregui, 2013: 24-26; Nieto, 20I2: 74). De la Casa e Illarregui señalan que el báculo, de probable uso episcopal, es ajeno a los «Cuerpos Santos», que procederían del norte de África pero, al igual que ellos, tampoco tiene su origen en Medinaceli (De la Casa e Illarregui, 20I3: 26 y 28). Basan esta conclusión en la ausencia de restos hispano-visigodos en la localidad. Sin embargo, creemos que es más sencillo y plausible aceptar que el conjunto de los restos se encontraba en posición primaria antes de su exhumación en $\mathrm{I5} 8 \mathrm{I}$, frente a la propuesta de su procedencia norteafricana y la extraña adición posterior de los vidrios y el báculo antes de su llegada a Medinaceli. De comprobarse en futuras investigaciones su adscripción cultural y su origen local, sería sugerente pensar que nos encontramos ante la sepultura de alguno de los primeros obispos de la sede episcopal segontina, lo que finalmente permitiría confirmar la identificación de Medinaceli con la Segontia del Itinerario Antonino ${ }^{24}$.

Pero de probarse en un futuro esta hipótesis, ¿ante qué Segontia estamos? Creemos difícil de explicar que pudiera tratarse de una ciudad que, estando recogida en el Itinerario de Antonino y habiendo sido promocionada jurídicamente en época Flavia $\left(\mathrm{Ga}^{-}\right.$ mo, 20I8: 3II), no hubiese sido citada en las obras

22 De la Casa e Illarregui proponen interpretar la decoración como colas de pez, flores de loto, espigas geométricas y cruces griegas. Los autores presentan un amplio estudio del objeto, concluyendo que se trata de un báculo de posible uso episcopal o abacial de los siglos viI-vin d. C. (De la Casa e Illarregui, 20I3: 24 y 25).

23 Agradecemos a Sergio Vidal Álvarez, conservador jefe del Departamento de Antigüedades Medievales del Museo Arqueológico Nacional, su valoración y comentarios acerca del báculo de Medinaceli.

24 Para confirmar esta propuesta creemos indispensable realizar análisis de ${ }^{14} \mathrm{C}$ a los restos óseos que se conservan de los cuerpos exhumados en 158r en la Colegiata de Santa María de Medinaceli. En cualquier caso, la adscripción cultural de los ajuares al periodo hispano-visigodo parece, en principio, totalmente coherente. de Plinio y Ptolomeo. Por tanto, la propuesta más plausible es su identificación con la Secontia del Convento Cluniense de Plinio y con la Segortia Lanca de Ptolomeo, ciudad adscrita a los arévacos por ambos autores. Así, definitivamente habría que desvincular Segortia Lanca del yacimiento de Las Quintanas-La Cuesta del Moro de Langa de Duero y relacionarla con el área de Medinaceli, donde se ubicaría esta ciudad en época tardorrepublicana e imperial romana.

\section{Conclusiones}

El territorio de la actual provincia de Soria estaría estructurado durante los periodos Celtibérico Tardío y Celtíbero-Romano por entre I5 y 35 oppi$d a$. De estos solo se conocen con seguridad los topónimos de tres de ellos: Uxama Argaela, Termes y Numancia. Para los restantes se han propuesto diferentes nombres recogidos en las fuentes clásicas y en los diversos documentos epigráficos sin que, a nuestro juicio, existan datos fehacientes que permitan confirmar las hipótesis propuestas. De entre todos, hemos estudiado los casos concretos de tres de ellos ubicados en los municipios de Langa de Duero, Medinaceli y Santa María de Huerta, concluyendo que en todos los casos existen más incógnitas que certezas respecto a sus nombres indígenas o romanos, aunque la revisión crítica del estado de la cuestión y de los datos arqueológicos permiten hacer algunas precisiones relevantes.

El yacimiento de las Ruinas Ciclópeas ubicado en las localidades de Santa María de Huerta y Granja de San Pedro tiene un carácter probablemente urbano. En el estado actual de las investigaciones, los diferentes indicios coinciden en señalar que esta ciudad-estado se fundó en un momento indeterminado comprendido entre las décadas finales del siglo iv y las primeras del siglo iII a. C. Los arqueólogos que recientemente han intervenido en el yacimiento coinciden en datar el abandono del oppidum a mediados del siglo in a. C. Es probable que en ese momento su población se trasladase al Cerro Villar de Monreal de Ariza que a partir de entonces concentró la población del entorno. Actualmente se acepta de forma generalizada la identificación de 
este último yacimiento con la ciudad tardorrepublicana y altoimperial de Arcobriga, mencionada en la tésera del pacto de Arcobriga, y citada también por Plinio, Ptolomeo, el Itinerario de Antonino y el Anónimo de Rávena. Respecto al oppidum de las Ruinas Ciclópeas, al no existir menciones escritas a una Arcobriga anterior al siglo I a. C. no podemos precisar su topónimo indígena, que podría coincidir con el de la posterior ciudad romana.

El yacimiento de Las Quintanas-La Cuesta del Moro de Langa de Duero ha sido considerado, desde su descubrimiento en la década de 1920 por Blas de Taracena, el solar de la ceca indígena de Sekotias Lakas y de la posterior ciudad romana de Segontia Lanca. Sin embargo, el temprano abandono del emplazamiento en la primera mitad del siglo i a. C.y la inexistencia, en el estado actual de las investigaciones, de un yacimiento altoimperial de entidad urbana en sus inmediaciones, cuestionan esta identificación. Esta duda se ve reforzada por la ausencia de monedas de la ceca Sekotias Lakas entre las localizadas en el yacimiento y por la rareza que representaría en la toponimia peninsular la perduración, no del topónimo principal de la población celtibérica y romana, sino la de su complemento. Por todo ello, la identificación del yacimiento de Las Quintanas-La Cuesta del Moro con la ciudad de Segontia Lanca debe considerarse, muy probablemente, incorrecta.

Por último, nos encontramos con el caso más complejo de los tres analizados, el de la ciudad romana ubicada bajo la actual Medinaceli. Creemos probado que debe rechazarse la identificación de esta urbe con los topónimos de Ocilis y Cortona, quedando solamente la propuesta de localización en este lugar de la mansio Segontia del Itinerario de Antonino. A la hora de valorar esta hipótesis surgen dos problemas: la ausencia en el casco urbano de Medinaceli de materiales celtibéricos; la escasez de restos altomedievales en el entorno inmediato de esta localidad que impide explicar la continuidad entre la ciudad romana y la posterior sede episcopal hispano-visigoda. Sin embargo, el estudio del territorio del Alto Tajuña, Alto Henares y Alto Jalón durante el Celtibérico Tardío permite proponer la existencia de un oppidum en el entorno inmediato de Medinaceli, probablemente junto al actual pueblo de Miño de Medinaceli, a menos de 7 kilómetros de la posterior ciudad romana. Por otra parte, $\mathrm{y}$ a falta de futuros análisis, la reinterpretación de los «Cuerpos Santos», exhumados en la antigua iglesia de San Román de Medinaceli en el siglo xvi, como los restos de los primeros obispos de la sede episcopal segontina, permitiría establecer una continuidad espacial directa entre las ruinas romanas de Medinaceli y la citada sede episcopal. De acuerdo a todo ello, si finalmente se acepta la ubicación de la mansio del Itinerario de Antonino en Medinaceli, debe valorarse como muy probable que esta Segontía sea la recogida por Plinio en el Convento Cluniense y por Ptolomeo entre los arévacos y, por tanto, la Segontia Lanca que hasta ahora se ubicaba en el yacimiento de Las Quintanas-La Cuesta del Moro de Langa de Duero. Sin embargo, y al igual que ocurre con el caso de las Ruinas Ciclópeas, identificar el oppidum concreto que otorgó su nombre a la posterior ciudad altoimperial es más complejo, pues esta englobaría el territorio de varios oppida próximos a ella, tales como: el ubicado en el entorno de la propia Medinaceli, El Castejón de Luzaga, La Torresaviñán y, quizá, los de El Villar de Aguaviva de la Vega y El Losar de El Atance. 
Bibliografía

Aguilera y Gamboa, E. (1909): El Alto Jalón. Descubrimientos arqueológicos. Establecimiento tipográfico de Fortanet. Madrid.

Alfaro Peña, E. (2018): Oppida y etnicidad en los confines septentrionales de la Celtiberia. Tesis doctoral. Universidad de Valladolid. Valladolid.

Alfayé Villa, S. (2003): "Materiales paleohispánicos inéditos en la obra de Juan Cabré”. Paleohispánica, 3: 9-29.

Beltrán Lloris, F. (2004): "Sobre la localización de Damania, Leónica, Osicerda y Orosis”. Paleohispánica, 4: 67-88.

Burillo Mozota, F. (2008): Los celtíberos. Etnias y estados. Crítica. Madrid.

Burillo Mozota, F. (20II): "Oppida y "ciudades-estado" celtibéricas”. Complutum, 22 (2): 277-295.

Caballero Casado, C.J. (1996): Asentamientos urbanos en la Celtiberia Citerior en la República y el Alto Imperio: la ciudad como elemento de romanización. Tesis doctoral. Universidad Complutense. Madrid.

Caballero Casado, C.J. (2016): "Vías romanas en la provincia de Guadalajara: un estado de la cuestión”. En G. Carrasco Serrano (coord.): Vias de comunicación romanas en Castilla-La Mancha. Ediciones de la Universidad de Castilla-La Mancha. Cuenca: 297-318.

Cabré Aguiló, J. (1917): Catálogo Monumental de Soria. Volumen 3: necrópolis celtibéricas. Manuscrito inédito.

Cabré Aguiló, J. (I922): "El marqués de Cerralbo II. Sus descubrimientos arqueológicos". Ibérica. El progreso de las ciencias y de sus aplicaciones, 453: 314-317.

Cabré Aguiló, J.: Relación de los objetos arqueológicos entregados por la Testamentaría del Excmo. Sr. Don Enrique de Aguilera y Gamboa, XVII Marqués de Cerralbo, al Museo Arqueológico Nacional de Madrid según la cláusula XXXVII del Testamento otorgado por dicho Excmo. Sr. Con fecha zo de Junio de 1922, ante el Notario de esta Corte, Don Luis Gallinal y Pedregal. Inventario Mecanografiado. Original en el Centro Documental de Arqueología y Patrimonio de la Universidad Autónoma de Madrid y copias en el Museo Arqueológico Nacional y Museo Cerralbo.
Capalvo Liesa, A. (1996): Celtiberia. Un estudio de fuentes literarias antiguas. Institución "Fernando el Católico". Zaragoza.

De la Casa, C. (20I2): Los cuerpos Santos de Medinaceli. Sumaria relación de noticias y cosas de los Santos Mártires: San Arcadio, Probo, Pascasio, Eutiquiano y Pablo niño. Ayuntamiento de Medinaceli. Soria.

De la Casa, C (2013): "Reliquias óseas de los cuerpos Santos de Medinaceli”. Revista de Soria, 79: 51-83.

De la Casa, C. e Illarregui, E. (2013): "Báculo eclesiástico de época visigoda en Medinaceli (Soria)". Butlletí de la Reial Acadèmia Catalana de Belles Arts de Sant Jordi, XXVII: 13-3I.

De Contreras, J.M. (1754): Los soles de Salamanca en el cielo de Medina. Imprenta de Antonio Pérez de Soto. Madrid.

De Mariana, J. (I854): Historia General de España. Biblioteca de Autores Españoles. Madrid.

Fernández Valverde, J. (ed.) (1979-1980): "Roderici Ximenii de Rada Historia Romanorum”. Habis, IO-II: 157-I82.

Fernández Valverde, J. (ed. y trad.) (1989): Historia de los hechos de España. Rodrigo Jiménez de Rada. Alianza Editorial. Madrid.

Fontán, A., García Arribas, I., Del Barrio, E. y Arribas, M.L. (ed. y trad.) (1998): Plinio el Viejo. Historia Natural. Libros III-VI. Editorial Gredos. Madrid.

Gamo Pazos, E. (2014): Epigrafía paleohispánica entre Carpetania y Celtiberia. La Ergástula. Madrid.

Gamo Pazos, E. (2018): La romanización de celtiberos y carpetanos en la Meseta Oriental. Zona Arqueológica, 22. Museo Arqueológico Regional de la Comunidad Autónoma de Madrid. Madrid.

García-Bellido, M.P.(1994): "Sobre la localización de Segobrix y las monedas del yacimiento de Clunia". Archivo Español de Arqueología, 169-170: 245-26o.

García-Bellido, M.P. (200I): Diccionario de cecas y pueblos hispánicos. Volumen II: Catálogo de cecas y pueblos. Consejo Superior de Investigaciones Científicas. Madrid.

García-Contreras, G. (2013): Los valles del Alto Henares en época andalusi: la organización del poblamiento y su relación con las explotaciones salineras. Tesis doctoral. Universidad de Granada. Granada. 
García-Contreras, G. (2014): "«Destructa atque dessolata» Acerca del lugar de Sigüenza en época altomedieval (ss. v-XII)". Debates de Arqueología Medieval, 4: 67-IIo.

Gómez Espelosín, F.J. (trad.) (2015): Estrabón. Geografía de Iberia. Alianza Editorial. Madrid.

Gómez Espelosín, F.J. (trad.) (2016): Apiano. Guerras Ibéricas. Aníbal. Alianza Editorial. Madrid.

Gómez Fraile,J.M. (200I): Los celtas en los valles altos del Duero y del Ebro. Universidad de Alcalá. Servicio de Publicaciones. Alcalá de Henares.

Gonzalo Monge, L.A. (20I4): "Las fortificaciones ciclópeas en el Alto Jalón”. En F. Burillo Mozota. y M. Chordá Pérez (eds.): VII Simposio sobre celtíberos. Nuevos hallazgos, nuevas interpretaciones. Centro de Estudios Celtibéricos de Segeda. Zaragoza: 4I-48.

Jimeno Martínez, A. (20II): "Las ciudades celtibéricas de la Meseta Oriental". Complutum, 22 (2): 223-276.

Jordán Cólera, C. (2019): Lengua y epigrafías celtibéricas. Universidad de Zaragoza. Zaragoza.

Liceras Garrido, R. (20I7): Paisaje y territorio celtibérico en el Alto Duero. Tesis doctoral. Universidad Complutense de Madrid. Madrid.

Lorrio Alvarado, J.A. (2005): Los celtíberos. Real Academia de la Historia-Universidad Complutense de Madrid. Madrid.

Lorrio Alvarado, J.A. y Sánchez de Prado, M.D. (2009): La necrópolis celtibérica de Arcóbriga. Monreal de Ariza, Zaragoza. Caesaraugusta, 80. Institución "Fernando el Católico". Zaragoza.

Lostal Pros, J. (1976): "La reducción de la ciudad de Arcóbriga según el Itinerario de Antonino”. Symposiom de Ciudades Augusteas II. Zaragoza: I39-I43.

Martínez Caballero, S. (2010): "«Segontia Lanca» (Hispania Citerior). Propuesta para la identificación de la ciudad celtíbera y romana”. Veleia, 27: I4I-I72.

Martino García, D. (2004): Las ciudades romanas de la Meseta Norte de la Península Ibérica: identificación, estatuto jurídico y jerarquías (ss. I-III d.C.). Tesis doctoral. Universidad Complutense de Madrid. Madrid.

Menéndez Pidal, R. (ed.) (1906): Primera Crónica General. Estoria de España. Nueva Biblioteca de Autores Españoles. Madrid.
Nieto Jiménez, M. (2012): Los Cuerpos Santos de Medinaceli, Mártires de Salamanca y el Convento de San Román: una reinterpretación. Aache. Guadalajara.

Pastor Eixarch, J.M. (1996): "Sobre la identificación de Segontia con Medinaceli y localización, junto a ella, de un posible «castra»". Celtiberia, 90: 215-233.

Pastor Eixarch, J.M. (20I4): “«Segontia, la que ahora llaman comúnmente Medinaceli» (Rodrigo Ximenez de Rada, II70-I247)”. En F. Burillo Mozota y M. Chordá Pérez (eds.): VII Simposio sobre celtíberos. Nuevos hallazgos, nuevas interpretaciones. Centro de Estudios Celtibéricos de Segeda. Zaragoza: Io3-III.

Quesada Sanz, F. (1997): El Armamento ibérico. Estudio tipológico, geográfico, funcional, social y simbólico de las armas en la Cultura ibérica (siglos VI-I a.C.). Éditions Monique Mergoil. Montagnac.

Rodríguez Cifuentes, M. (dir. y coord.) (20I4): Formación e intercambio cultural en el Alto Jalón. Nilo Industria Gráfica. Madrid.

Roldán Hervás, J.M. y Caballero Casado, C. (20I4): Itinera Hispana. Estudio de las vías romanas en Hispania a partir del Itinerario de Antonino, el Anónimo de Ravena y los Vasos de Vicarello. El Nuevo Miliario, I7. Madrid.

Royo Guillén, J.I. y Gómez Lecumberri, F. (2005-2006): "La «Cueva de las Cazoletas» de Monreal de Ariza (Zaragoza) y sus grabados rupestres: un santuario celtibérico al aire libre". Kalathos, 24-25: 293-32I.

Stückelberger. A. y Grabhoff. G. (ed.y trad.) (20I7): Ptolemaios. Handbuch der Geographie. Schwabe Verlag. Basel.

Tabernero Galán, C. (2017): “Segontia Lanca y el conjunto arqueológico de «Las Quintanas-La Cuesta del Moro» en Langa de Duero (Soria)". Anejos de Segovia Histórica, 2: 9I-Io9.

Tabernero Galán, C., Heras Fernández, H., Benito Batanero, J.P. y Sanz Aragonés, A. (2005): "Segontia Lanka”. En A. Chaín Galán y J.I. De la Torre Echávarri (coords.): Celtíberos. Tras la estela de Numancia. Diputación Provincial de Soria. Soria: 197-204. 
Taracena Aguirre, B. (1929): Excavaciones en las provincias de Soria y Logroño. Memoria de la Junta Superior de Excavaciones y Antigüedades, Io3. Madrid.

Taracena Aguirre, B. (1932): Excavaciones en la provincia de Soria. Junta Superior de Excavaciones y Antigüedades, II9. Madrid.

Taracena Aguirre, B. (194I): Carta Arqueológica de España. Soria. Consejo Superior de Investigaciones Científicas-Instituto Diego Velázquez. Madrid.
Torija López, A. y Baquedano Beltrán, I. (2007): "Las tesserae de la Colección Cerralbo. Viejas conocidas, nuevas perspectivas". Paleohispáni$c a, 7: 269-336$.

Zurita, J. (1600): Itinerarium Antonini Augusti et burdigalense ... : quorum hoc nunc primum est editum: illud ad diuersos manufc. codices E impressos comparatum, emendatum, \& Hieronymi Suritae ... commentario explicatum. Coloniae Agrippinae: in Officina Birckmannica. 